\title{
Use of Antimicrobial Films and Edible Coatings Incorporating Chemical and Biological Preservatives to Control Growth of Listeria monocytogenes on Cold Smoked Salmon
}

\author{
Hudaa Neetoo ${ }^{1}$ and Fawzi Mahomoodally ${ }^{2}$ \\ ${ }^{1}$ Department of Agriculture and Food Science, Faculty of Agriculture, University of Mauritius, Mauritius \\ ${ }^{2}$ Department of Health Sciences, Faculty of Science, University of Mauritius, Mauritius
}

Correspondence should be addressed to Fawzi Mahomoodally; f.mahomoodally@uom.ac.mu

Received 27 February 2014; Revised 9 May 2014; Accepted 7 June 2014; Published 25 June 2014

Academic Editor: Vasilis P. Valdramidis

Copyright (C) $2014 \mathrm{H}$. Neetoo and F. Mahomoodally. This is an open access article distributed under the Creative Commons Attribution License, which permits unrestricted use, distribution, and reproduction in any medium, provided the original work is properly cited.

\begin{abstract}
The relatively high incidence of Listeria monocytogenes in cold smoked salmon (CSS) is of concern as it is a refrigerated processed food of extended durability (REPFED). The objectives of this study were to compare and optimize the antimicrobial effectiveness of films and coatings incorporating nisin (Nis) and sodium lactate (SL), sodium diacetate (SD), potassium sorbate (PS), and/or sodium benzoate (SB) in binary or ternary combinations on CSS. Surface treatments incorporating Nis $(25000 \mathrm{IU} / \mathrm{mL})$ in combination with PS $(0.3 \%)$ and SB $(0.1 \%)$ had the highest inhibitory activity, reducing the population of $L$. monocytogenes by a maximum of $3.3 \log \mathrm{CFU} / \mathrm{cm}^{2}$ (films) and $2.9 \log \mathrm{CFU} / \mathrm{cm}^{2}$ (coatings) relative to control samples after 10 days of storage at $21^{\circ} \mathrm{C}$. During refrigerated storage, coatings were more effective in inhibiting growth of L. monocytogenes than their film counterparts. Cellulosebased coatings incorporating Nis, PS, and SB reduced the population of L. monocytogenes, and anaerobic and aerobic spoilage flora by a maximum of $4.2,4.8$, and $4.9 \log \mathrm{CFU} / \mathrm{cm}^{2}$, respectively, after 4 weeks of refrigerated storage. This study highlights the effectiveness of cellulose-based edible coatings incorporating generally regarded as safe (GRAS) natural and chemical antimicrobials to inhibit the development of L. monocytogenes and spoilage microflora thus enhancing the safety and quality of CSS.
\end{abstract}

\section{Introduction}

Listeria monocytogenes has long been established as an important food-borne pathogen with a fatality rate of $25-$ $30 \%$ [1]. However, the incidence of food-related listeriosis has increased dramatically in the last few years, where $L$. monocytogenes has been listed in the top five highest-ranking pathogens with respect to the total cost of foodborne illness in the United States in terms of loss of income by the affected individual, cost of health care, loss of productivity due to absenteeism, costs of investigations of an outbreak, loss of income due to closure of businesses, consumer litigations, or losses of product sales when consumers avoid particular products [2].

L. monocytogenes infection has been associated with consuming a variety of meat, poultry, fish, and dairy products
[3]. The prevalence of this organism in cold smoked fish in particular is relatively high and typically between 10 to $40 \%[4,5]$. This high prevalence is likely due to the low temperature inherent with cold smoking process. Indeed, this condition would be congenial for the proliferation of L. monocytogenes if the raw salmon harbored the pathogen or acquired it from the processing environment [6]. Hence, processing of cold smoked salmon (CSS) includes no recognizable critical control point for L. monocytogenes and therefore this product cannot be completely free of this pathogen [7]. For this reason, smoked seafood, including CSS, has been categorized as having a high risk of listeriosis [7].

Since postprocess contamination of smoked fish with L. monocytogenes is highly problematic, antimicrobial additives are sought after to prevent growth of this bacterium 
in food products and to ensure safety. Several studies have reported the effectiveness of nisin (a polycyclic antibacterial peptide) in delaying and reducing growth of Listeria spp. in model systems $[8,9]$ and in RTE products [10] including CSS $[11,12]$. Nisin is a heat-stable bacteriocin that kills sensitive pathogens by disrupting their cell membranes, leading to leakage of cellular material and ultimately cell death [13]. In the United States, nisin has a generally regarded as safe (GRAS) status for use in pasteurized processed cheese and petitions have been filed for its use in other products as well $[14,15]$. The efficacy of nisin as an antimicrobial agent in raw or minimally processed seafood is limited by several factors [16]. These include the potential for proteolytic activity in raw food that would cause rapid degradation of nisin [17], as well as the rapid decrease in the antimicrobial activity of nisin due to increased resistance of the pathogens [18].

Thus, a multiple-hurdle approach relying on the combination of nisin with other antimicrobials, such as chemical preservatives, is desirable. Sodium lactate (SL) is a GRAS additive that is widely used to enhance flavor, control microbial growth, and increase shelf life of meat, poultry, and fish products [19-22]. The use of lactates as antimicrobial agents is primarily due to their ability to reduce $\mathrm{pH}$ and water activity. Currently, the addition of SL is allowed at $4.8 \%$ for the decontamination of seafood products [16]. Sodium diacetate (SD), a derivative of acetic acid, is used to achieve an antimicrobial effect in baked goods, fats and oils, gravies and sauces, snack foods, meat products, and soups and soup mixes, as well as to flavor these foods [16]. It is also a GRAS substance recommended for use at levels not exceeding $0.25 \%$ [16]. Potassium sorbate (PS) is a salt of sorbic acid and common usage levels of PS in various food products have ranged from 0.5 to $1.0 \%$ [23]. Depending on the processing conditions, PS is usually applied to whole or eviscerated fish or fillets, prior to or immediately after smoking [24]. Sorbates may be used at a level not exceeding $0.3 \%$, and at this concentration sorbates do not contribute to flavor [23]. Sodium benzoate (SB) is also used as an antimicrobial agent and is currently allowed at $0.1 \%$ [16]. These chemical preservatives have been shown to inhibit growth of grampositive bacterial pathogens such as $L$. monocytogenes in media, meat [25-30], and seafood [31, 32].

Antimicrobial coatings and films allow the controlled diffusion and gradual release of embedded antimicrobials onto the food surface [33]. Significant inroads have been made in antimicrobial packaging to control the proliferation of L. monocytogenes on CSS. Neetoo et al. [34] found that alginate coatings supplemented with $2.4 \% \mathrm{SL}$ and $0.25 \% \mathrm{SD}$ significantly delayed the growth of $L$. monocytogenes in CSS during a 30-day storage at $4^{\circ} \mathrm{C}$. Moreover, Ye et al. [35] showed that prior frozen storage enhanced the effect of alginatebased coatings and chitosan-based films incorporated with SL $(1.2$ or $2.4 \% \mathrm{w} / \mathrm{w})$ or SD $(0.125$ or $0.25 \% \mathrm{w} / \mathrm{w})$ against L. monocytogenes on CSS during subsequent refrigerated storage. Reductions ranging from 0.5 to $4.5 \log \mathrm{CFU} / \mathrm{cm}^{2}$ compared to uncoated samples were reported. Growth of $L$. monocytogenes on the surface of CSS was inhibited by wheyprotein films incorporating a lactoperoxidase system [36].
Seydim and Sarikus [37] showed that strong antimicrobial activity of oregano essential oil impregnated in whey-protein isolate-based edible films against L. monocytogenes. Similarly, Tammineni et al. [38] developed an edible antimicrobial film using potato peel waste incorporating oregano essential oil against L. monocytogenes on CSS. The films reduced the inoculum by greater than $2 \log \mathrm{CFU} / \mathrm{g}$ during storage at $4^{\circ} \mathrm{C}$ for 28 days. However, all aforementioned studies have tested the antilisterial efficacy of films or coatings in isolation and lack a systematic comparison of the relative efficacy of each approach.

The objective of this study was to compare cellulosecoated plastic films and edible cellulose-based coatings incorporating binary or ternary combinations of food-approved antimicrobials to inhibit growth of $L$. monocytogenes and spoilage microflora on vacuum-packaged CSS during refrigerated storage $\left(4^{\circ} \mathrm{C}\right)$.

\section{Materials and Methods}

2.1. Listeria monocytogenes Inoculum Preparation. Five L. monocytogenes strains, PSU1 (serotype 1/2a), PSU21 (serotype 4b), PSU9 (serotype 1/2b), F5069 (serotype 4b), and Scott A (serotype $4 \mathrm{~b}$ ) (Courtesy of Rolf Joerger, University of Delaware), were used. The strains were maintained on tryptic soy agar plus $0.6 \%$ yeast extract (TSAYE) plates and stored at $4^{\circ} \mathrm{C}$. Each strain was grown independently in tryptic soy broth plus $0.6 \%$ yeast extract (TSBYE) for $24 \mathrm{~h}$ at $37^{\circ} \mathrm{C}$ and a loopful of each overnight culture was transferred to $10 \mathrm{~mL}$ of fresh TSBYE and incubated at $37^{\circ} \mathrm{C}$ for $24 \mathrm{~h}$. On the day of the experiment, $1 \mathrm{~mL}$ volume of each culture was combined to provide a five-strain mixture and then readjusted with $0.1 \%$ peptone water to a final cell density of ca. $10^{8} \mathrm{CFU} / \mathrm{mL}$, which served as the inoculum. Serial dilutions were plated onto TSAYE plates and incubated at $37^{\circ} \mathrm{C}$ for $24 \mathrm{~h}$ to determine cell numbers.

2.2. Inoculation of CSS Samples. Freshly processed CSS (Salmo salar) was obtained from a producer. It was kept frozen at $-20^{\circ} \mathrm{C}$ and thawed at $2 \pm 2^{\circ} \mathrm{C}\left(<4^{\circ} \mathrm{C}\right)$ for 1 day immediately before use. Slices of CSS were punched aseptically into $5.7 \mathrm{~cm}$ diameter round pieces weighing $10 \pm 1 \mathrm{~g}$. The samples were surface-inoculated with a $10^{8} \mathrm{CFU} / \mathrm{mL}$ dilution of the five-strain cocktail of $L$. monocytogenes to achieve final concentrations of $10^{5} \mathrm{CFU} / \mathrm{cm}^{2}$ (or $5 \times 10^{5} \mathrm{CFU} / \mathrm{g}$ ) of salmon surface. After inoculation, salmon samples were kept at room temperature for $30 \mathrm{~min}$ to allow bacterial attachment. L. monocytogenes populations in CSS are generally low (1$10^{3} \mathrm{CFU} / \mathrm{g}$ ) with $90-99 \%$ of cases below $10^{2} \mathrm{CFU} / \mathrm{g}$ and less than $1 \%$ between $10^{3}$ and $10^{4} \mathrm{CFU} / \mathrm{g}$ as reported by Jørgensen and Huss [39] and Farber and Peterkin [40]. However, pathogen levels as high as $10^{5}-10^{7} \mathrm{CFU} / \mathrm{g}$ have also been reported previously [1]. In this experiment, we used an initial load of $\sim 5 \log \mathrm{CFU} / \mathrm{g}$ to provide a worst-case scenario. From 
a risk assessment point of view, using an inoculum size of $5 \log$ CFU/g to test the antilisterial efficacy of antimicrobial films and coatings provides greater confidence or assurance.

\subsection{Antilisterial Effectiveness of Films and Coatings Incorpo- rating Binary Combinations of Antimicrobials}

2.3.1. Preparation of Coating Solution. Methylcellulose (MC; $7.0 \mathrm{~g}$ ) and hydroxypropylmethylcellulose (HPMC; $3.0 \mathrm{~g}$ ) were mixed with $200 \mathrm{~mL}$ of $95 \%$ ethanol and $200 \mathrm{~mL}$ of sterile distilled water and stirred to which $6 \mathrm{~mL}$ of polyethylene glycol 400 was subsequently added. This coating stock solution was then supplemented with the various antimicrobial preparations. Briefly, $1.3 \mathrm{~g}$ of nisin was dissolved in $60 \mathrm{~mL}$ of $0.02 \mathrm{M}$ acetic acid, and $12 \mathrm{~mL}$ of the prepared nisin solution was then supplemented with either $1.29 \mathrm{~g} \mathrm{SD}, 1.54 \mathrm{~g}$ PS, $0.51 \mathrm{~g}$ $\mathrm{SB}$, or $2.57 \mathrm{~g}$ of a- $60 \% \mathrm{SL}$ syrup. The antimicrobial solution was then made up to $50 \mathrm{~mL}$ with the MC/HPMC carrier solution. The solution was sufficient to coat 10 salmon discs.

2.3.2. Preparation of Films. The MC and HPMC were mixed with ethanol and water to prepare a coating solution as described above. The coating solution was then supplemented with the various antimicrobials. Briefly, $3.0 \mathrm{~g}$ nisin was dissolved in $60 \mathrm{~mL} 0.02 \mathrm{M}$ acetic acid, and $12 \mathrm{~mL}$ of the prepared nisin solution was then supplemented with $3.0 \mathrm{~g} \mathrm{SD}, 3.6 \mathrm{~g}$ PS, $1.2 \mathrm{~g} \mathrm{SB}$, or $6 \mathrm{~g}$ of $60 \%$ of SL syrup. The antimicrobial solution was then made up to $42 \mathrm{~mL}$ with the MC/HPMC carrier solution. The solution was then used to coat 3 glass plates, lined with LDPE films covering a surface area of $400 \mathrm{~cm}^{2}$ each, using a thin layer chromatography (TLC) plate coater.

2.3.3. Treatment of Inoculated CSS Samples with Antimicrobial Coatings and Films. The inoculated CSS discs were coated with a $500 \mu \mathrm{L}$ aliquot of a HPMC/MC coating solution containing nisin $(25,000 \mathrm{IU} / \mathrm{mL})$ alone or in combination with SL $(0.3 \%)$, SD $(0.25 \%)$, PS $(0.3 \%)$, or SB $(0.1 \%)$ as summarized in Table 1 . The samples were then air-dried by leaving them in a laminar-flow hood under ventilation for $20 \mathrm{~min}$. Samples were then flipped and similarly coated with an equal volume of the antimicrobial coating solution followed by drying. Alternatively, inoculated CSS discs were wrapped in different antimicrobial-coated films as shown in Table 1.

Inoculated samples without films or coatings were also prepared as untreated controls. Controls and treated samples (film-wrapped or coated) were then inserted into $3 \mathrm{~mm}$ thick high barrier pouches and subsequently sealed using a vacuum-packaging machine. The samples were stored at room temperature $\left(21^{\circ} \mathrm{C}\right)$ for 10 days and analyzed microbiologically every other day.

2.3.4. Enumeration of L. monocytogenes from Samples. For microbial analysis, the package was aseptically cut and the sample transferred to a sterile stomacher bag that contained $40 \mathrm{~mL}$ of $0.1 \%$ sterile peptone water and stomached for $2 \mathrm{~min}$. Serial dilutions were made in $0.1 \%$ peptone water and counts of $L$. monocytogenes were determined by an overlay method
[41]. Briefly, the serial dilutions were spread-plated on solidified TSAYE and the plates were incubated at $35^{\circ} \mathrm{C}$ for $3 \mathrm{~h}$. where Modified Oxford Medium $(\sim 7 \mathrm{~mL})$ tempered at $45^{\circ} \mathrm{C}$ was overlaid on the plates. These plates were then incubated at $35^{\circ} \mathrm{C}$ for $48 \mathrm{~h}$ and small black colonies with black haloes were counted. Occasionally, suspect colonies were confirmed using a BAX for Screening/Listeria monocytogenes PCR assay. The numbers of $L$. monocytogenes per $\mathrm{cm}^{2}$ of salmon were calculated by dividing the total count of $L$. monocytogenes per salmon disc by the total surface area $\left(51.4 \mathrm{~cm}^{2}\right)$. The absence of the pathogen in the CSS samples was confirmed by a primary enrichment in UVM broth (Difco Laboratories) and a secondary enrichment in Fraser broth (Difco Laboratories) according to the USDA Microbiology Laboratory Guidebook [42].

2.4. Antilisterial Effectiveness of Films and Coatings Incorporating Ternary Combinations of Antimicrobials. The CSS samples were inoculated to a final concentration of $10^{5} \mathrm{CFU} / \mathrm{cm}^{2}$ of salmon surface. Antimicrobials with the highest antilisterial activity (PS and SB) were selected for further testing. Inoculated salmon discs were coated with a $500 \mu \mathrm{L}$ aliquot of HPMC/MC coating solution on each side containing Nis $(25000 \mathrm{IU} / \mathrm{mL})$ with PS $(0,0.15$ or $0.3 \%)$ or Nis $(25000 \mathrm{IU} / \mathrm{mL})$ with PS $(0,0.15$, or $0.3 \%)$ and SB $(0$, 0.05 , or $0.1 \%)$. The samples were air-dried and packaged. In addition, inoculated CSS samples were wrapped with LDPE films coated with a solution containing Nis $(25000 \mathrm{IU} / \mathrm{mL})$ with PS $(0,0.15$, or $0.3 \%)$ or Nis $(25000 \mathrm{IU} / \mathrm{mL})$ with PS $(0$, 0.15 , or $0.3 \%)$ and SB $(0,0.05$, or $0.1 \%)$. Samples were then packaged and stored at $21^{\circ} \mathrm{C}$ for 10 days. The formulations for the various binary or ternary combinations of antimicrobials incorporated in films or coatings are summarized in Table 2. Samples were then microbiologically analyzed for $L$. monocytogenes as described earlier.

\subsection{Effectiveness of Films and Coatings Containing Selected} Antimicrobial Combinations against L. monocytogenes and Spoilage Microflora. The CSS samples were surface-inoculated to a final concentration of approximately $10^{3} \mathrm{CFU} / \mathrm{cm}^{2}$ (or $\left.5 \times 10^{3} \mathrm{CFU} / \mathrm{g}\right)$. Uninoculated samples were also prepared. Inoculated and uninoculated samples were wrapped with film or coated with an antimicrobial coating solution, packaged, and stored at $4^{\circ} \mathrm{C}$ for 4 weeks. The combinations of antimicrobials incorporated in films and coatings for the refrigerated storage study are summarized in Table 3.

Inoculated samples were analyzed weekly for L. monocytogenes as described previously. Uninoculated samples were also analyzed weekly for spoilage aerobic and anaerobic bacteria. Spoilage anaerobic bacterial counts were determined by plating on Liver Veal Agar and plates incubated in anaerobic jars with anaerobic GasPak (BBL) for two days at $35^{\circ} \mathrm{C}$. Aerobic bacterial counts were determined by plating onto TSAYE and plates incubated aerobically for two days at $35^{\circ} \mathrm{C}$.

2.6. Statistical Analysis. Three independent trials were conducted for all experiments. Colony counts were converted to $\log _{10} \mathrm{CFU} / \mathrm{cm}^{2}$ and means and standard deviations were 
TABLE 1: Binary combinations of antimicrobials incorporated in films and edible coatings.

\begin{tabular}{lc}
\hline Antimicrobial films & Antimicrobial coatings \\
\hline Control (plain LDPE films) & Plain MC/HPMC \\
Nis $(25000 \mathrm{IU} / \mathrm{mL})$ & $\mathrm{Nis}(25000 \mathrm{IU} / \mathrm{mL})$ \\
Nis $(25000 \mathrm{IU} / \mathrm{mL})+\mathrm{SD}(0.25 \%)$ & $\mathrm{Nis}(25000 \mathrm{IU} / \mathrm{mL})+\mathrm{SD}(0.25 \%)$ \\
Nis $(25000 \mathrm{IU} / \mathrm{mL})+$ SB $(0.1 \%)$ & $\mathrm{Nis}(25000 \mathrm{IU} / \mathrm{mL})+\mathrm{SB}(0.1 \%)$ \\
Nis $(25000 \mathrm{IU} / \mathrm{mL})+$ SL $(0.3 \%)$ & $\mathrm{Nis}(25000 \mathrm{IU} / \mathrm{mL})+\mathrm{SL}(0.3 \%)$ \\
Nis $(25000 \mathrm{IU} / \mathrm{mL})+$ PS $(0.3 \%)$ & $\mathrm{Nis}(25000 \mathrm{IU} / \mathrm{mL})+\mathrm{PS}(0.3 \%)$ \\
\hline
\end{tabular}

TABLE 2: Binary and ternary combinations of antimicrobials incorporated in films and edible coatings.

\begin{tabular}{lcc}
\hline Nisin $(\mathrm{IU} / \mathrm{mL})$ & PS $(\%)$ & SB $(\%)$ \\
\hline 0 & 0.0 & 0.0 \\
25000 & 0.0 & 0.0 \\
25000 & 0.0 & 0.05 \\
25000 & 0.0 & 0.1 \\
25000 & 0.15 & 0.0 \\
25000 & 0.15 & 0.05 \\
25000 & 0.15 & 0.1 \\
25000 & 0.3 & 0.0 \\
25000 & 0.3 & 0.05 \\
25000 & 0.3 & 0.1 \\
\hline
\end{tabular}

TABLE 3: Combinations of antimicrobials incorporated in films and coatings for the refrigerated storage study.

\begin{tabular}{lcc}
\hline Nisin $(\mathrm{IU} / \mathrm{mL})$ & PS $(\%)$ & SB $(\%)$ \\
\hline 0 & 0 & 0 \\
25000 & 0.3 & 0 \\
25000 & 0.3 & 0.1 \\
\hline
\end{tabular}

calculated using Microsoft Excel. A Tukey-Kramer test was used to determine differences in the populations of L. monocytogenes, aerobes, and anaerobes on CSS samples. Significant differences were considered at the 95\% confidence level $(P<$ $0.05)$.

\section{Results}

3.1. Antilisterial Effectiveness of Films and Coatings Incorporating Binary Combinations of Antimicrobials. The fate of L. monocytogenes on CSS slices treated with different binary combinations of antimicrobials in films and coatings is represented in Figures 1(a) and 1(b), respectively. The initial load of the inoculum was about $6 \log \mathrm{CFU} / \mathrm{cm}^{2}$. After 2 days, the control (untreated) samples had higher counts than all other treatments with the Nis + SB $\left(5.2 \log \mathrm{CFU} / \mathrm{cm}^{2}\right)$ and $\mathrm{Nis}+\mathrm{PS}\left(4.8 \log \mathrm{CFU} / \mathrm{cm}^{2}\right)$ coatings showing significantly $(P<0.05)$ lower counts than the control groups. After
10 days, L. monocytogenes population on samples treated with $\mathrm{Nis}+\mathrm{SB}\left(4.9-6.3 \log \mathrm{CFU} / \mathrm{cm}^{2}\right)$ and Nis + PS (4.3$4.7 \log \mathrm{CFU} / \mathrm{cm}^{2}$ ) was appreciably lower compared to the control untreated samples $\left(7.7 \log \mathrm{CFU} / \mathrm{cm}^{2}\right)$ although the results were not statistically significant $(P>0.05)$.

3.2. Antilisterial Effectiveness of Films and Coatings Incorporating Ternary Combinations of Antimicrobials. Figures 2(a) and 2(b) show the effect of film and coating treatments incorporating ternary combinations of antimicrobials on the growth of L. monocytogenes on CSS. The initial counts of L. monocytogenes on CSS were about $5.6 \log \mathrm{CFU} / \mathrm{cm}^{2}$ and increased steadily over the 10 -day period reaching a maximum count of $7.6 \log \mathrm{CFU} / \mathrm{cm}^{2}$. Over the storage period, the counts for all treatments were consistently lower than the control for either method of antimicrobial application. Ternary combinations of Nis $(25000 \mathrm{IU} / \mathrm{mL})$, PS $(0.15$ or $0.3 \%)$, and SB ( 0.05 or $0.1 \%)$ in films and coatings significantly $(P<0.05)$ inhibited the growth of L. monocytogenes after 10 days, lowering the population by $2.0-3.3 \log \mathrm{CFU} / \mathrm{cm}^{2}$ and 2.2-2.9 $\log \mathrm{CFU} / \mathrm{cm}^{2}$, respectively.

3.3. Effectiveness of Films and Coatings Containing Selected Antimicrobial Combinations against L. monocytogenes and Spoilage Microflora. The two combined treatments chosen for this study were Nis + PS (0.3\%) and Nis + PS (0.3\%) + SB $(0.1 \%)$. L. monocytogenes counts on inoculated CSS treated with antimicrobial films and coatings incorporating Nis + PS or Nis + PS + SB are shown in Figures 3(a) and 3(b), respectively. The mean population of $L$. monocytogenes on CSS recovered just after inoculation was $2.7 \log \mathrm{CFU} / \mathrm{cm}^{2}$. The pathogen grew unhindered in untreated samples stored at $4^{\circ} \mathrm{C}$, reaching approximately $4.8 \log \mathrm{CFU} / \mathrm{cm}^{2}$ after 4 weeks. All the antimicrobial treatments (films or coatings) brought about a significant reduction $(P<0.05)$ in the population achieving reductions of $2.0-2.7 \log \mathrm{CFU} / \mathrm{cm}^{2}$ by the end of the storage period. Ternary combinations of Nis $(25000 \mathrm{IU} / \mathrm{mL})$ with PS $(0.3 \%)$ and SB $(0.1 \%)$ were more effective than binary combinations of Nis $(25000 \mathrm{IU} / \mathrm{mL})$ with PS $(0.3 \%)$ for either method of application although the difference was not statistically significant $(P>0.05)$.

The total anaerobic and aerobic counts of the uninoculated samples are shown in Figures 4(a) and 4(b). Throughout 


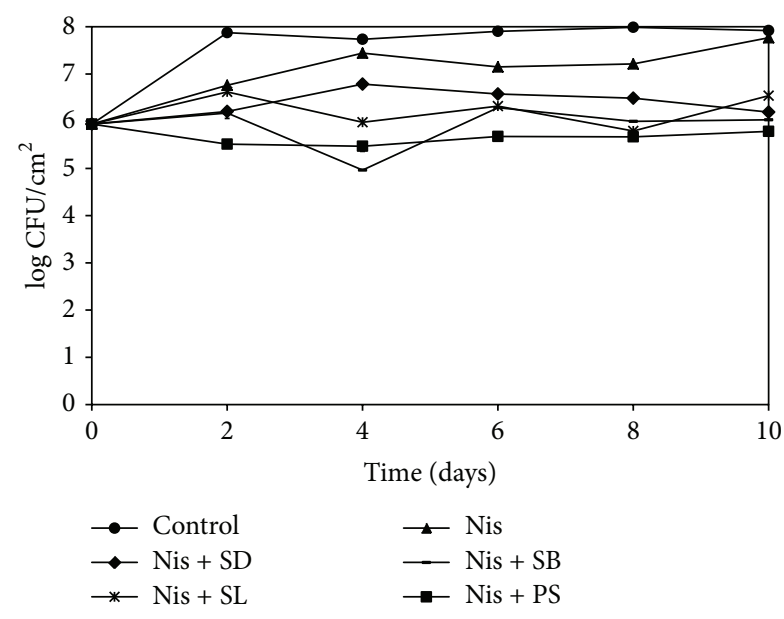

(a)

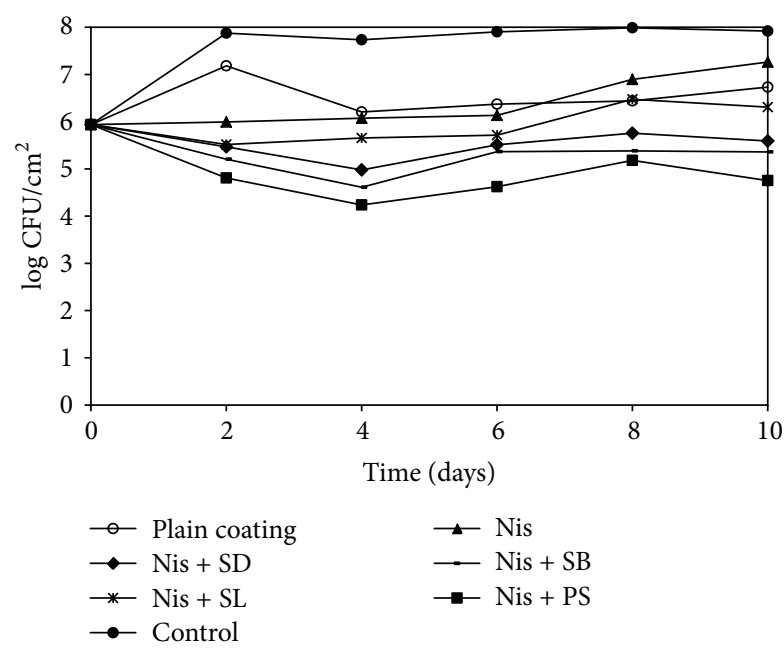

(b)

FIGURE 1: Fate of L. monocytogenes on CSS slices packaged with antimicrobial films (a) and coatings (b) incorporating nisin (25000 IU/mL), SL (0.3\%), SD (0.25\%), SB (0.1\%), and PS (0.3\%) and stored at ambient temperature. Error bars are omitted from the chart for the sake of clarity.

the storage study, the population of mesophilic aerobic and anaerobic bacteria in treated samples was consistently lower than their untreated counterpart with a maximum reduction of $4.9-5.6 \log \mathrm{CFU} / \mathrm{cm}^{2}$ by the end of the storage period. Although both films and coatings were effective in delaying the development of background flora, coatings incorporating $\mathrm{Nis}+\mathrm{PS}$ and Nis $+\mathrm{PS}+\mathrm{SB}$ resulted in greater $(P>0.05)$ population reduction than their film counterparts.

\section{Discussion}

Cold smoked salmon (CSS) is considered a high-risk food because the temperature used during the cold smoking operation is not lethal to L. monocytogenes. In addition, CSS

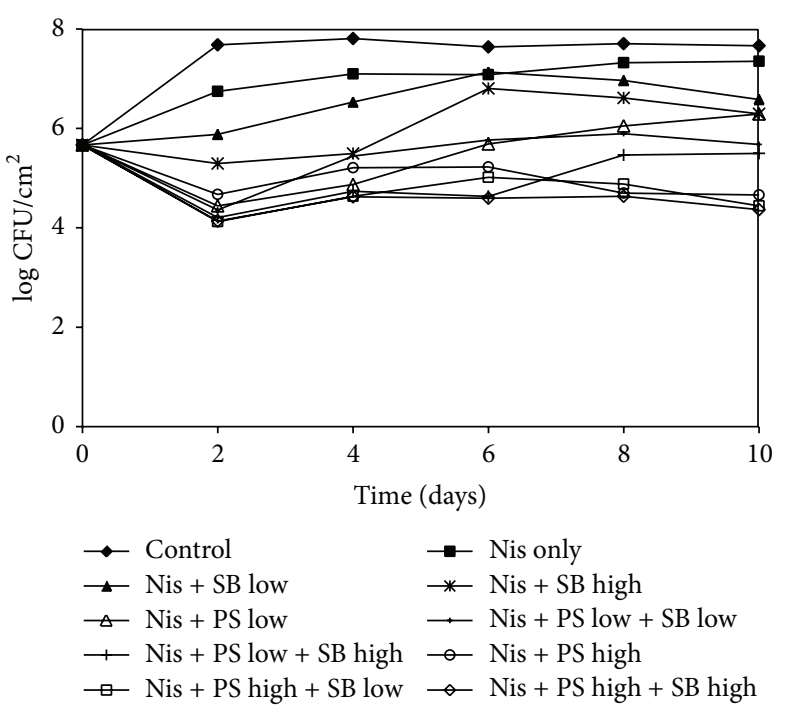

(a)

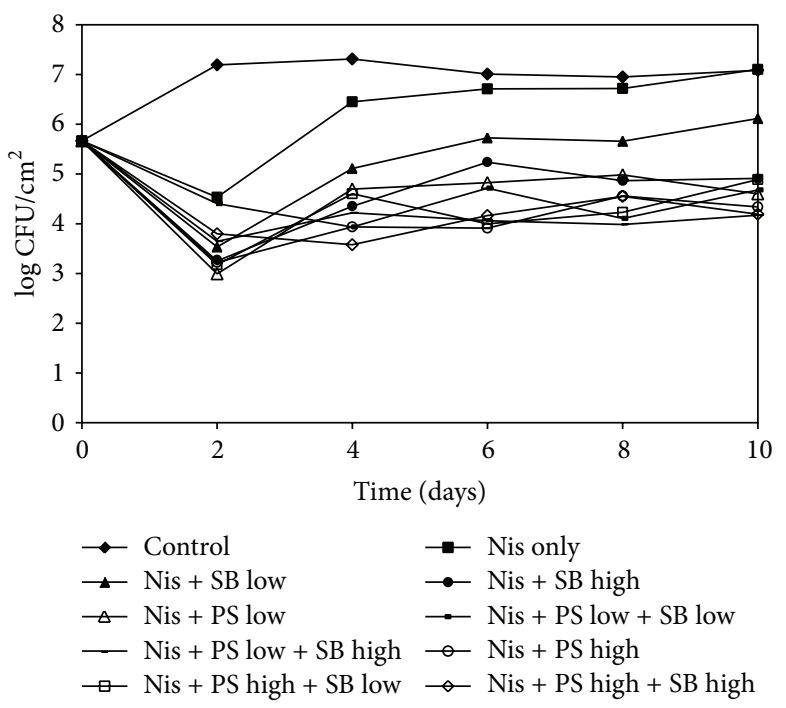

(b)

FIgURE 2: Populations of L. monocytogenes on CSS slices packaged with antimicrobial films (a) and coatings (b) incorporating nisin $(25000 \mathrm{IU} / \mathrm{mL})$ with PS at low $(0.15 \%)$ or high $(0.3 \%)$ concentrations or SB at low $(0.05 \%)$ or high concentrations $(0.1 \%)$ and stored at ambient temperature. Error bars are omitted from the chart for the sake of clarity.

is a type of minimally processed food, also called Refrigerated Processed Foods of Extended Durability (REPFED) [43], and concern has been expressed about the survival and growth of this pathogen during the product's prolonged shelf life. During the past decade, there have been several recalls of smoked fish because of L. monocytogenes contamination [44] and it has been generally assumed that the presence of the pathogen on fish products is the result of postprocess contamination on the surface of the product [44]. Moreover, several studies $[45,46]$ have reported that bacterial population in 


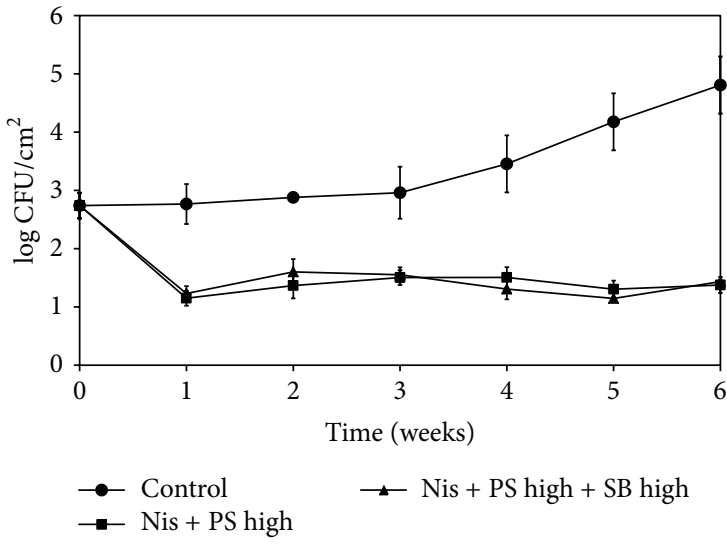

(a)

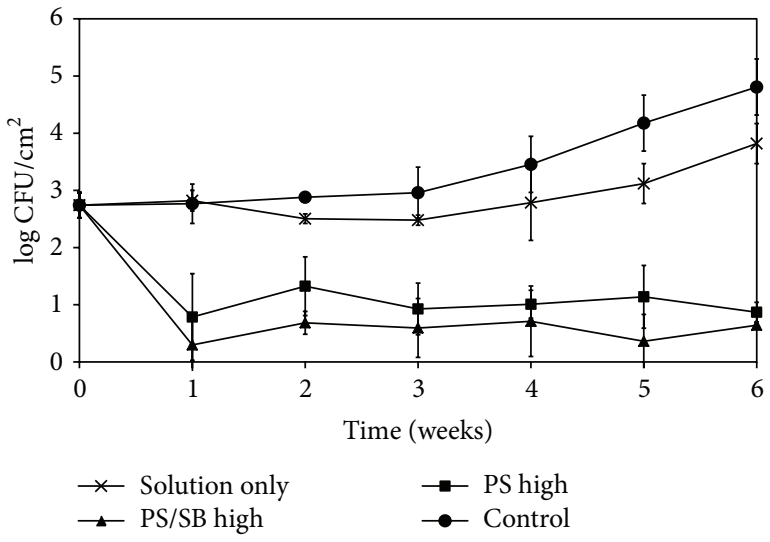

(b)

FIGURE 3: Development of Listeria monocytogenes on CSS slices treated with antimicrobial films (a) and coatings (b) incorporating Nis $(25000 \mathrm{IU} / \mathrm{mL})$ with high concentrations of PS $(0.3 \%)$ with or without $\mathrm{SB}(0.1 \%)$ during storage at $4^{\circ} \mathrm{C}$.

cold smoked salmon can increase by 3-4 $\log \mathrm{CFU} / \mathrm{g}$ in a few weeks during refrigerated storage.

Several forms of interventions have thus been recommended to reduce the risks from L. monocytogenes in these products: (1) elimination or reduction of L. monocytogenes on the outside surface of frozen or fresh fish before filleting, (2) prevention of recontamination and growth of $L$. monocytogenes during all stages of processing, and (3) the inhibition of any possible survivors or recontamination during processing and distribution [44]. Numerous papers have been published on the inhibition of L. monocytogenes in cold smoked fish using physical interventions including gamma irradiation [47], X-ray irradiation [48], E-beam [49], highpressure processing [50], chemical preservatives [51-53], natural antimicrobials $[54,55]$, and protective cultures [56, 57]. Extensive research has also been performed in the last decade on the application of antimicrobial packaging to specifically enhance the safety and extend the shelf life of fish and fish products. However, despite considerable efforts, this area of research remains challenging. This is primarily due to the intrinsic characteristics of fishery products themselves, namely, their almost neutral $\mathrm{pH}$ and presence of endogenous proteolytic enzymes [58], which can decrease the efficacy of acid antimicrobials and bacteriocins, respectively. Indeed, the effectiveness of salts of organic acids as antimicrobials is known to differ widely depending on the $\mathrm{pH}$ of the food matrix [16]. Moreover, in cold processed foods such as CSS, proteases can affect nisin stability [59].

Because of the aforementioned reasons, films and coatings have garnered more interest by virtue of their ability to not only provide a barrier against gases and moisture [60], but also act as carriers of antimicrobials. Alishahi and Aïder [61] pointed to the promising application of chitosan as an excellent antimicrobial, used stand alone or in combination, in herring, cod, cold smoked salmon, and trout. Reductions of the order of 1-3 $\log \mathrm{CFU} / \mathrm{g}$ of L. monocytogenes, following chitosan application on CSS, have been reported previously
[32, 62]. Moreover, Gómez-Estaca et al. [63] coated cold smoked sardines with gelatin-based films (4\%) enriched with oregano $(1.25 \%)$ and rosemary extracts $(20 \%)$ and showed that growth of TVC was retarded by $2 \log$ and $2.5 \mathrm{log}$ (respectively) compared to uncoated samples after 16 days of storage. Lu et al. [64] tested, in snakehead fish fillets, alginate coatings $(20 \mathrm{mg} / \mathrm{mL})$ with cinnamon EO $(10 \mu \mathrm{L} / \mathrm{mL})$, EDTA $(150 \mu \mathrm{g} / \mathrm{mL})$, and nisin $(2000 \mathrm{IU} / \mathrm{mL})$ alone and with their mixes against Pseudomonas spp., TVC, and psychrotrophic bacteria during storage at $4^{\circ} \mathrm{C}$. The inhibitory effect of those antimicrobials on TVC followed the order: cinnamon + EDTA + nisin or cinnamon $(5.5 \log \mathrm{CFU} / \mathrm{g})>$ nisin + EDTA $(1.5 \log$ CFU/g) compared to controls. Song et al. [65] reported that composite films of barley bran protein and gelatin containing grapefruit seed extract brought about a reduction of $0.5 \log \mathrm{CFU} / \mathrm{g}$ of $E$. coli $\mathrm{O} 157: \mathrm{H7}$ and $L$. monocytogenes on salmon after 15 days of storage at $4^{\circ} \mathrm{C}$. The antilisterial effect of a calcium alginate coating incorporating oyster lysozyme in the presence or absence of nisin on the surface of smoked salmon was also investigated previously [66]. Although the coatings supplemented with nisin and lysozyme were able to delay or slow down the growth of L. monocytogenes, the treatment was not highly inhibitory. Taken together, these findings point to the highly variable antimicrobial efficacy of edible films and coatings (reductions of $0.5-5.5 \log \mathrm{CFU} / \mathrm{g}$ ), which is dependent on the type, concentration, and combination of antimicrobials as well as the test product of interest.

In our current study, the antimicrobial efficacy of cellulose-coated films and cellulose-based coatings incorporating Nis, SL, SD, PS, and SB in different concentrations and combinations was compared. Findings revealed that coatings incorporating nisin $(25000 \mathrm{IU} / \mathrm{mL})$, PS $(0.3 \%)$, and SB $(0.1 \%)$ were most effective and reduced the population of $L$. monocytogenes and anaerobic and aerobic spoilage flora by a maximum of $4.2,4.8$, and $4.9 \log \mathrm{CFU} / \mathrm{cm}^{2}$, respectively, after 4 weeks of refrigerated storage. The listeriostatic activity 


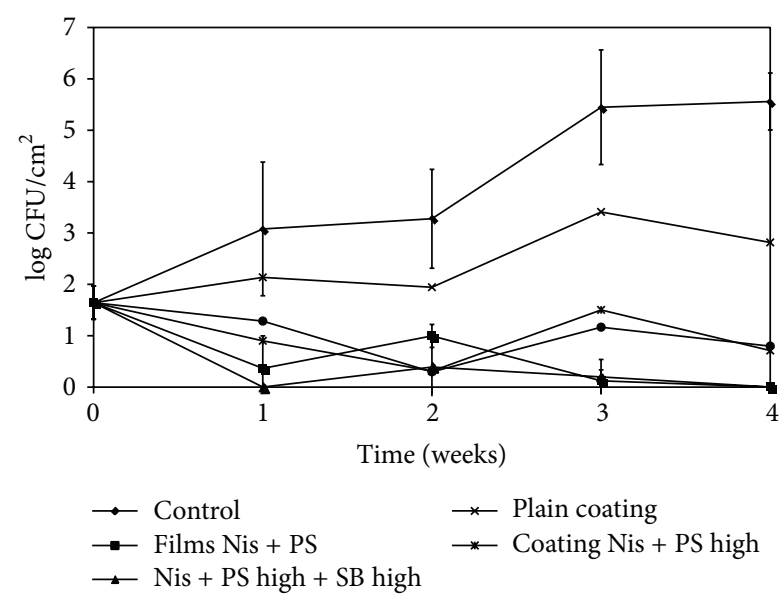

(a)

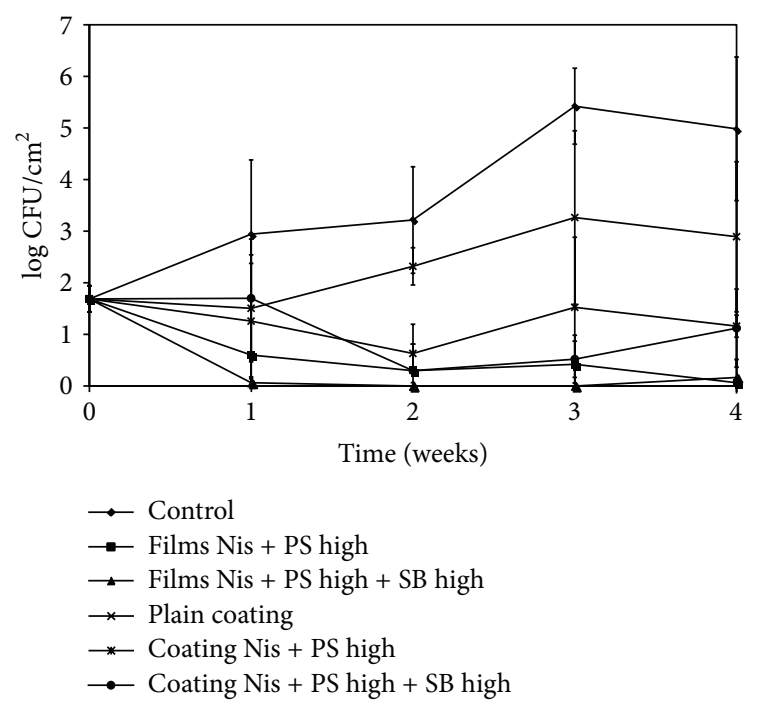

(b)

FIGURE 4: Development of mesophilic anaerobes (a) and aerobes (b)on CSS slices treated with antimicrobial films and coatings incorporating Nis $(25000 \mathrm{IU} / \mathrm{mL})$ with high concentrations of PS $(0.3 \%)$ with or without SB $(0.1 \%)$ during storage at $4^{\circ} \mathrm{C}$.

of nisin on cold smoked fish, at levels ranging from $100 \mathrm{IU} / \mathrm{mL}$ to $2000 \mathrm{IU} / \mathrm{mL}$, alone or in combination with $\mathrm{LAB}$ protective cultures [67], or natural antimicrobials such as lyzozyme and polylysine [68], or chemical preservatives such as lactate or diacetate [69] has been demonstrated previously. Unlike our findings, Tang et al. [69] reported that a binary combination of Nisin and lactate had greatest antilisterial effectiveness. On the other hand, Wan Norhana et al. [70] showed that ternary combinations of nisin-PS-EDTA reduced the population of $L$. monocytogenes as well as psychrotrophic bacteria on vacuumpackaged shrimps by 1.3 and $4.0 \log \mathrm{CFU} / \mathrm{g}$, respectively. Neetoo et al. [31] also indicated that PS had considerable antilisterial activity when combined with nisin on CSS pâté and fillets. Sorbates have also been shown to kill or inhibit $L$. monocytogenes previously $[25,30,71]$ and its activity can be further enhanced by the addition of nisin [72]. Other authors $[72,73]$ have similarly demonstrated the listeriostatic and listericidal ability of Nis + PS in vitro as well as on packaged beef kept at refrigeration temperature for up to 4 weeks.

Moreover, our data indicate that edible coatings containing nisin $(25000 \mathrm{IU} / \mathrm{mL})+$ PS $(0.3 \%)$ or nisin $(25000 \mathrm{IU} / \mathrm{mL})$ + PS $(0.3 \%)+$ SB $(0.1 \%)$ reduced the population of $L$. monocytogenes and spoilage bacteria to a greater extent than their film counterparts. Recent studies have also highlighted the application of organic acids or their salts alone [74] or in combination with other hurdles such as $\mathrm{CO}_{2}[75]$ to delay the development of spoilage flora on salmon. Other overriding advantages of edible coatings are that they reduce packaging waste, they are environment-friendly, and they are low-priced $[76,77]$ when compared to films, which are synthetic packaging materials. Hence, edible coatings constitute an alternative, environmentally sustainable, and cost-effective technology
[78] for the salmon industry. In the current work, the carrier of choice was cellulose, a widely available, low-cost, versatile polysaccharide biopolymer [77] and a compatible matrix for the embedded antimicrobials. Polysaccharide-based edible coatings are more popular than other hydrocolloids because they are generally transparent, cohesive, and homogeneous with adequate mechanical properties [60,79].

Antimicrobials tested in this study are regarded as direct food additives and their application is thus limited by governmental legislation [16]. Sorbates may be directly added to food or incorporated into the packaging, at a level not exceeding $0.3 \%$ [23] while sodium benzoate is currently allowed at $0.1 \%$ [16]. Levels of PS (0.15 and $0.3 \%)$ and SB $(0.05$ and $0.1 \%)$ investigated in the current experiments were within legal limits of 0.3 and $0.1 \%$, respectively. Presently, nisin is commercially added to smoked salmon in the United States (US) to control the growth of L. monocytogenes, although the maximum allowable level of this additive in smoked fish has not been stipulated [80]. The US Food and Drug Administration (FDA) has set a maximum limit of $10,000 \mathrm{IU} / \mathrm{g}$ for use of nisin in processed cheese although no such upper limit exists in Australia, France, or Great Britain $[80,81]$. In the current study, the level of nisin incorporated into the films and coatings was $25000 \mathrm{IU} / \mathrm{mL}$, translating to a maximum concentration of $2500 \mathrm{IU} / \mathrm{g}$ assuming complete leaching into the food product.

In recognition of the fact that CSS is (i) susceptible to postprocess surface contamination by L. monocytogenes, (ii) a refrigerated processed food of extended durability, and (iii) consumed without any heat-killing step, it is regarded as a high-risk product. This study reiterates the usefulness of antimicrobial packaging for cold smoked salmon, 
and it also underscores the effectiveness of cellulose-based coatings incorporating GRAS antimicrobials to control the development of pathogens and spoilage microbiota, thereby enhancing the microbiological safety and quality of this product.

\section{Conflict of Interests}

The authors declare no conflict of interests. Neither author has any commercial associations that might create a conflict of interests in connection with this paper.

\section{Acknowledgments}

The authors wish to thank Drs. Mu Ye, Haiqiang Chen, and Rolf Joerger (University of Delaware, USA) for their technical and nontechnical assistance throughout this project as well as Dr. Larry Cogburn (University of Delaware) for his excellent editorial assistance.

\section{References}

[1] J. M. Farber and P. I. Peterkin, "Listeria monocytogenes, a foodborne pathogen ," Microbiological Reviews, vol. 55, no. 3, pp. 476-511, 1991.

[2] R. L. Scharff, Health-Related Costs from Foodborne Illness in the United States The produce Safety Project at Georgetown University, 2010, http://www.producesafetyproject.org/assets/files/ Health-Related-Foodborne-Illness-Costs-Report.pdf.

[3] M. Hamon, H. Bierne, and P. Cossart, "Listeria monocytogenes: a multifaceted model," Nature Reviews Microbiology, vol. 4, no. 6, pp. 423-434, 2006.

[4] I. Azevedo, M. Regalo, C. Mena et al., "Incidence of Listeria spp. in domestic refrigerators in Portugal," Food Control, vol. 16, no. 2, pp. 121-124, 2005.

[5] H. Miettinen and G. Wirtanen, "Ecology of Listeria spp. in a fish farm and molecular typing of Listeria monocytogenes from fish farming and processing companies," International Journal of Food Microbiology, vol. 112, no. 2, pp. 138-146, 2006.

[6] S. C. Dass, E. J. Cummins, and N. Abu-Ghannam, "Prevalence and typing of Listeria monocytogenes strains in retail vacuumpacked cold-smoked salmon in the Republic of Ireland," Journal of Food Safety, vol. 31, no. 1, pp. 21-27, 2011.

[7] G. Wulff, L. Gram, P. Ahrens, and B. F. Vogel, "One group of genetically similar Listeria monocytogenes strains frequently dominates and persists in several fish slaughter- and smokehouses," Applied and Environmental Microbiology, vol. 72, no. 6, pp. 4313-4322, 2006.

[8] I. S. Boziaris and G.-J. E. Nychas, "Effect of nisin on growth boundaries of Listeria monocytogenes Scott A, at various temperatures, $\mathrm{pH}$ and water activities," Food Microbiology, vol. 23, no. 8, pp. 779-784, 2006.

[9] M. Jamuna, S. T. Babusha, and K. Jeevaratnam, "Inhibitory efficacy of nisin and bacteriocins from Lactobacillus isolates against food spoilage and pathogenic organisms in model and food systems," Food Microbiology, vol. 22, no. 5, pp. 449-454, 2005.

[10] I. Geornaras, P. N. Skandamis, K. E. Belk et al., "Postprocess control of Listeria monocytogenes on commercial frankfurters formulated with and without antimicrobials and stored at $10^{\circ} \mathrm{C}$," Journal of Food Protection, vol. 69, no. 1, pp. 53-61, 2006.
[11] H. Zuckerman and R. B. Avraham, "Control of growth of L. monocytogenes in fresh salmon using Microgard and Nisin," LWT_Food Science and Technology, vol. 35, no. 6, pp. 543-548, 2002.

[12] M. Al-Holy, J. Ruiter, M. Lin, D.-H. Kang, and B. Rasco, "Inactivation of Listeria innocua in nisin-treated salmon (Oncorhynchus keta) and sturgeon (Acipenser transmontanus) caviar heated by radio frequency," Journal of Food Protection, vol. 67, no. 9, pp. 1848-1854, 2004.

[13] K. Winkowski, R. D. Ludescher, and T. J. Montville, "Physicochemical characterization of the nisin-membrane interaction with liposomes derived from Listeria monocytogenes," Applied and Environmental Microbiology, vol. 62, no. 2, pp. 323-327, 1996.

[14] Food and Drug Administration (FDA) and M. G. W. aldbaum Company, "Filing of petition for affirmation of GRAS status," Food and Drug Administration: Federal Register, vol. 59, pp. 12582-12583, 1994.

[15] Food and Drug Administration (FDA) and Aplin \& B arrett Ltd, "Filing of petition for affirmation of GRAS status," Food and Drug Administration: Federal Register, vol. 60, p. 64167, 1995.

[16] B. A. Crozier-Dodson, M. Carter, and Z. Zheng, "Formulating food safety: an overview of antimicrobial ingredients," Food Safety Magazine, pp. 75-76, 2005.

[17] I. M. Aasen, S. Markussen, T. Møretrø, T. Katla, L. Axelsson, and K. Naterstad, "Interactions of the bacteriocins sakacin P and nisin with food constituents," International Journal of Food Microbiology, vol. 87, no. 1-2, pp. 35-43, 2003.

[18] M. Al-Holy, M. Lin, and B. Rasco, "Destruction of Listeria monocytogenes in sturgeon (Acipenser transmontanus) caviar by a combination of nisin with chemical antimicrobials or moderate heat," Journal of Food Protection, vol. 68, no. 3, pp. 512-520, 2005.

[19] D. D. Duxbury, "Sodium lactate extends shelf life, improves flavor of cooked beef," Food Processing, vol. 51, pp. 46-47, 1990.

[20] J. W. Lamkey, F. W. Leak, W. B. Tuley, D. D. Johnson, and R. L. West, "Assessment of sodium lactate addition to fresh pork sausage," Journal of Food Science, vol. 56, no. 1, pp. 220-223, 1991.

[21] L. S. Papadopoulos, R. K. Miller, G. R. Acuff, C. Vanderzant, and H. R. Cross, "Effect of sodium lactate on microbial and chemical composition of cooked beef during storage," Journal of Food Science, vol. 56, no. 2, pp. 341-347, 1991.

[22] L. S. Papadopoulos, R. K. Miller, L. J. Ringer, and H. R. Cross, "Sodium lactate effect on sensory characteristics, cooked meat color and chemical composition," Journal of Food Science, vol. 56, no. 3, pp. 621-626, 1991.

[23] "CNFP Technical Advisory Panel Review," 2002, http:// www.ams.usda.gov/AMSv1.0/getfile?dDocName=STELPRDC5067082.

[24] D. F. Chichester and W. Tanner, "Antimicrobial food additives," in Handbook of Food Additives, pp. 115-185, CRC Press, Boca Raton, Fla, USA, 2nd edition, 1972.

[25] M. A. El-Shenawy and E. H. Marth, "Inhibition or inactivation of Listeria monocytogenes by sorbic acid," Journal of Food Protection, vol. 51, pp. 842-847, 1988.

[26] M. Islam, J. Chen, M. P. Doyle, and M. Chinnan, "Control of Listeria monocytogenes on Turkey frankfurters by generallyrecognized-as-safe preservatives," Journal of Food Protection, vol. 65, no. 9, pp. 1411-1416, 2002.

[27] M. Islam, J. Chen, M. P. Doyle, and M. Chinnan, "Effect of selected generally recognized as safe preservative sprays on 
growth of Listeria monocytogenes on chicken luncheon meat," Journal of Food Protection, vol. 65, no. 5, pp. 794-798, 2002.

[28] M. C. Robach and J. N, "Sofos, Use of sorbates in meat products, fresh poultry and poultry products: a review," Journal of Food Protection, vol. 45, pp. 374-383, 1982.

[29] J. Samelis, J. N. Sofos, M. L. Kain, J. A. Scanga, K. E. Belk, and G. C. Smith, "Organic acids and their salts as dipping solutions to control Listeria monocytogenes inoculated following processing of sliced pork bologna stored at $4 \circ \mathrm{c}$ in vacuum packages," Journal of Food Protection, vol. 64, no. 11, pp. 1722-1729, 2001.

[30] H. J. Wederquist, J. N. Sofos, and G. R. Schmidt, "Listeria monocytogenes inhibition in refrigerated vacuum packaged turkey bologna by chemical additives," Journal of Food Science, vol. 59, no. 3, pp. 498-500, 1994.

[31] H. Neetoo, M. Ye, and H. Chen, "Potential antimicrobials to control Listeria monocytogenes in vacuum-packaged coldsmoked salmon pâté and fillets," International Journal of Food Microbiology, vol. 123, no. 3, pp. 220-227, 2008.

[32] Z. Jiang, H. Neetoo, and H. Chen, "Efficacy of freezing, frozen storage and edible antimicrobial coatings used in combination for control of Listeria monocytogenes on roasted turkey stored at chiller temperatures," Food Microbiology, vol. 28, no. 7, pp. 1394-1401, 2011.

[33] S. Min and J. M. Krochta, "Inhibition of Penicillium commune by edible whey protein films incorporating lactoferrin, lactoferrin hydrolysate, and lactoperoxidase systems," Journal of Food Science, vol. 70, no. 2, pp. M87-M94, 2005.

[34] H. Neetoo, M. Ye, and H. Chen, "Bioactive alginate coatings to control Listeria monocytogenes on cold-smoked salmon slices and fillets," International Journal of Food Microbiology, vol. 136, no. 3, pp. 326-331, 2010.

[35] M. Ye, H. Neetoo, and H. Chen, "Prior frozen storage enhances the effect of edible coatings against Listeria monocytogenes on cold-smoked salmon during subsequent refrigerated storage," Journal of Applied Microbiology, vol. 111, no. 4, pp. 865-876, 2011.

[36] S. Min, L. J. Harris, and J. M. Krochta, "Antimicrobial effects of lactoferrin, lysozyme, and the lactoperoxidase system and edible whey protein films incorporating the lactoperoxidase system against Salmonella enterica and Escherichia coli O157:H7," Journal of Food Science, vol. 70, no. 7, pp. 332-338, 2005.

[37] A. C. Seydim and G. Sarikus, "Antimicrobial activity of whey protein based edible films incorporated with oregano, rosemary and garlic essential oils," Food Research International, vol. 39, no. 5, pp. 639-644, 2006.

[38] N. Tammineni, G. Ünlü, and S. C. Min, "Development of antimicrobial potato peel waste-based edible films with oregano essential oil to inhibit Listeria monocytogenes on cold-smoked salmon," International Journal of Food Science and Technology, vol. 48, no. 1, pp. 211-214, 2013.

[39] L. V. Jørgensen and H. H. Huss, "Prevalence and growth of Listeria monocytogenes in naturally contaminated seafood," International Journal of Food Microbiology, vol. 42, no. 1-2, pp. 127-131, 1998.

[40] J. M. Farber and P. I. Peterkin, "Listeria monocytogenes," in The Microbiological Safety and Quality of Foods, B. M. Lund, T. C. Baird-Parker, and G. W. Gould, Eds., pp. 1178-1232, Aspen, Gaithersburg, Md, USA, 2000.

[41] D. Kang and D. Y. C. Fung, "Thin agar layer method for recovery of heat-injured Listeria monocytogenes," Journal of Food Protection, vol. 62, no. 11, pp. 1346-1349, 1999.

[42] United States Department of Agriculture, "Microbiology laboratory guidebook," 1998, http://www.fsis.usda.gov/wps/portal/
searchhelp/help/!ut/p/a0/04_Sj9CPykssy0xPLMnMz0vMAfGjzOINAg3MDC2dDbz8LQ3dDDz9wgL9vZ2dDdwNTfULsh0VASWBaOU!/?1dmy\&current=true\&urile=wcm $\% 3$ Apath $\% 3 \mathrm{~A} /$ fsis content/internet/main/topics/science/laboratoriesand-procedures/guidebooks-and methods/microbiologylaboratory-guidebook/microbiology-laboratory-guidebook.

[43] D. A. A. Mossel and C. B. Struijk, "Public health implication of refrigerated pasteurized ("sous-vide") foods," International Journal of Food Microbiology, vol. 13, no. 3, pp. 187-206, 1991.

[44] K. C. Jinneman, M. M. Wekell, and M. W. Eklund, "Incidence and behavior of Listeria monocytogenes in fish and seafood," in Listeria, Listeriosis and Food Safety, E. T. Ryser and E. H. Marth, Eds., pp. 617-655, CRC Press, Boca Raton, Fla, USA, 2007.

[45] M. Ye, H. Neetoo, and H. Chen, "Effectiveness of chitosancoated plastic films incorporating antimicrobials in inhibition of Listeria monocytogenes on cold-smoked salmon," International Journal of Food Microbiology, vol. 127, no. 3, pp. 235-240, 2008.

[46] P. Gambarin, C. Magnabosco, M. N. Losio et al., "Listeria monocytogenes in ready-to-eat seafood and potential Hazards for the consumers," International Journal of Microbiology, vol. 2012, Article ID 497635, 10 pages, 2012.

[47] H. M. Badr, "Control of the potential health hazards of smoked fish by gamma irradiation," International Journal of Food Microbiology, vol. 154, no. 3, pp. 177-186, 2012.

[48] B. S. M. Mahmoud, R. Coker, and Y.-C. Su, "Reduction in Listeria monocytogenes and spoilage bacteria on smoked catfish using X-ray treatments," Letters in Applied Microbiology, vol. 54, no. 6, pp. 524-529, 2012.

[49] M. Medina, M. C. Cabeza, D. Bravo et al., "A comparison between E-beam irradiation and high pressure treatment for cold-smoked salmon sanitation: microbiological aspects," Food Microbiology, vol. 26, no. 2, pp. 224-227, 2009.

[50] B. Gudbjornsdottir, A. Jonsson, H. Hafsteinsson, and V. Heinz, "Effect of high-pressure processing on Listeria spp. and on the textural and microstructural properties of cold smoked salmon," LWT_Food Science and Technology, vol. 43, no. 2, pp. 366-374, 2010

[51] L. Feliciano, J. Lee, J. A. Lopes, and M. A. Pascall, "Efficacy of sanitized ice in reducing bacterial load on fish fillet and in the water collected from the melted ice," Journal of Food Science, vol. 75, no. 4, pp. M231-M238, 2010.

[52] S. Kin, M. W. Schilling, B. S. Smith et al., "Potassium acetate and potassium lactate enhance the microbiological and physical properties of marinated catfish fillets," Journal of Food Science, vol. 76, no. 4, pp. S242-S250, 2011.

[53] S. Kin, M. Wes Schilling, T. Kim et al., "Effects of potassium lactate and acetate on listeria monocytogenes inhibition, physicochemical and sensory properties of smoked catfish fillets," Journal of Aquatic Food Product Technology, vol. 21, no. 4, pp. 338-350, 2012.

[54] T. Katla, T. Møretrø, I. M. Aasen, A. Holck, L. Axelsson, and K. Naterstad, "Inhibition of Listeria monocytogenes in cold smoked salmon by addition of sakacin $\mathrm{P}$ and/or live Lactobacillus sakei cultures," Food Microbiology, vol. 18, no. 4, pp. 431-439, 2001.

[55] F. B. dos Reis, V. M. de Souza, M. R. S. Thomaz, L. P. Fernandes, W. P. de Oliveira, and E. C. P. De Martinis, "Use of Carnobacterium maltaromaticum cultures and hydroalcoholic extract of Lippia sidoides Cham. against Listeria monocytogenes in fish model systems," International Journal of Food Microbiology, vol. 146, no. 3, pp. 228-234, 2011. 
[56] L. Nilsson, Y. Y. Ng, J. N. Christiansen, B. L. Jørgensen, D. Grótinum, and L. Gram, "The contribution of bacteriocin to inhibition of Listeria monocytogenes by Carnobacterium piscicola strains in cold-smoked salmon systems," Journal of Applied Microbiology, vol. 96, no. 1, pp. 133-143, 2004.

[57] A. Gálvez, H. Abriouel, R. L. López, and N. B. Omar, "Bacteriocin-based strategies for food biopreservation," International Journal of Food Microbiology, vol. 120, no. 1-2, pp. 51-70, 2007.

[58] V. P. Lougovois and V. R. Kyrana, "Freshness quality and spoilage of chill-stored fish," in Food Policy, Control and Research, A. P. Riley, Ed., pp. 35-86, Nova Science, 2005.

[59] J. Delves-Broughton, "Nisin as a food preservative," Food Australia, vol. 57, no. 12, pp. 525-527, 2005.

[60] T. Bourtoom and M. S. Chinnan, "Preparation and properties of rice starch-chitosan blend biodegradable film," LWT-Food Science and Technology, vol. 41, no. 9, pp. 1633-1641, 2008.

[61] A. Alishahi and M. Aïder, "Applications of chitosan in the seafood industry and aquaculture: a review," Food and Bioprocess Technology, vol. 5, no. 3, pp. 817-830, 2012.

[62] S. M. Ojagh, M. Rezaei, S. H. Razavi, and S. M. H. Hosseini, "Effect of chitosan coatings enriched with cinnamon oil on the quality of refrigerated rainbow trout," Food Chemistry, vol. 120, no. 1, pp. 193-198, 2010.

[63] J. Gómez-Estaca, P. Montero, B. Giménez, and M. C. GómezGuillén, "Effect of functional edible films and high pressure processing on microbial and oxidative spoilage in cold-smoked sardine (Sardina pilchardus)," Food Chemistry, vol. 105, no. 2, pp. 511-520, 2007.

[64] F. Lu, Y. Ding, X. Ye, and D. Liu, "Cinnamon and nisin in alginate-calcium coating maintain quality of fresh Northern snakehead fish fillets," LWT_Food Science and Technology, vol. 43, no. 9, pp. 1331-1335, 2010.

[65] H. Y. Song, Y. J. Shin, and K. B. Song, "Preparation of a barley bran protein-gelatin composite film containing grapefruit seed extract and its application in salmon packaging," Journal of Food Engineering, vol. 113, no. 4, pp. 541-547, 2012.

[66] S. Datta, M. E. Janes, Q.-. Xue, J. Losso, and J. F. La Peyre, "Control of Listeria monocytogenes and Salmonella anatum on the surface of smoked salmon coated with calcium alginate coating containing oyster lysozyme and nisin," Journal of Food Science, vol. 73, no. 2, pp. M67-M71, 2008.

[67] A. Concha-Meyer, R. Schöbitz, C. Brito, and R. Fuentes, "Lactic acid bacteria in an alginate film inhibit Listeria monocytogenes growth on smoked salmon," Food Control, vol. 22, no. 3-4, pp. 485-489, 2011.

[68] H. Takahashi, M. Kashimura, S. Miya et al., "Effect of paired antimicrobial combinations on Listeria monocytogenes growth inhibition in ready-to-eat seafood products," Food Control, vol. 26, no. 2, pp. 397-400, 2012.

[69] S. Tang, K. J. Boor, T. M. Bergholz, M. J. Stasiewicz, and M. Wiedmann, "Efficacy of different antimicrobials on inhibition of Listeria monocytogenes growth in laboratory medium and on cold-smoked salmon," International Journal of Food Microbiology, vol. 165, no. 3, pp. 265-275, 2013.

[70] M. N. Wan Norhana, S. E. Poole, H. C. Deeth, and G. A. Dykes, "Effects of nisin, EDTA and salts of organic acids on Listeria monocytogenes, Salmonella and native microflora on fresh vacuum packaged shrimps stored at $4 \circ$ C, Food Microbiology, vol. 31, no. 1, pp. 43-50, 2012.
[71] J. N. Sofos, "Sorbic acid," in Natural Food Antimicrobial Systems, A. S. Naidu, Ed., pp. 637-660, CRC Press, Boca Raton, Fla, USA, 2000.

[72] S. Buncic, C. M. Fitzgerald, R. G. Bell, and J. A. Hudson, "Individual and combined listericidal effects of sodium lactate, potassium sorbate, nisin and curing salts at refrigeration temperature," Journal of Food Safety, vol. 15, no. 3, pp. 247-264, 1995.

[73] S. M. Avery and S. Buncic, "Antilisterial effects of a sorbatenisin combination in vitro and on packaged beef at refrigeration temperature," Journal of Food Protection, vol. 60, no. 9, pp. 10751080, 1997.

[74] K. I. Sallam, "Chemical, sensory and shelf life evaluation of sliced salmon treated with salts of organic acids," Food Chemistry, vol. 101, no. 2, pp. 592-600, 2007.

[75] B. C. Schirmer, R. Heiberg, T. Eie et al., "A novel packaging method with a dissolving $\mathrm{CO}_{2}$ headspace combined with organic acids prolongs the shelf life of fresh salmon," International Journal of Food Microbiology, vol. 133, no. 1-2, pp. 154-160, 2009.

[76] P. Suppakul, J. Miltz, K. Sonneveld, and S. W. Bigger, "Active packaging technologies with an emphasis on antimicrobial packaging and its applications," Journal of Food Science, vol. 68, no. 2, pp. 408-420, 2003.

[77] J. H. Han and A. Gennadios, "Edible films and coatings: a review," in Innovations in Food Packaging, J. H. Han, Ed., pp. 239-262, Elsevier/Academic Press, Amsterdam, The Netherlands, 2005.

[78] C. A. Campos, L. N. Gerschenson, and S. K. Flores, "Development of edible films and coatings with antimicrobial activity," Food and Bioprocess Technology, vol. 4, no. 6, pp. 849-875, 2011.

[79] T. Bourtoom, "Edible protein films: properties enhancement," International Food Research Journal, vol. 16, no. 1, pp. 1-9, 2009.

[80] E. Jones, V. Salin, and G. W. Williams, "Nisin and the market for commercial bacteriocins," Consumer and Product Research CP-01-05, Texas Agribusiness Market Research Center, Texas A\&M University, College Station, Tex, USA, 2005.

[81] B. K. Tiwari, V. P. Valdramidis, C. P. O’Donnell, K. Muthukumarappan, P. Bourke, and P. J. Cullen, "Application of natural antimicrobials for food preservation," Journal of Agricultural and Food Chemistry, vol. 57, no. 14, pp. 5987-6000, 2009. 

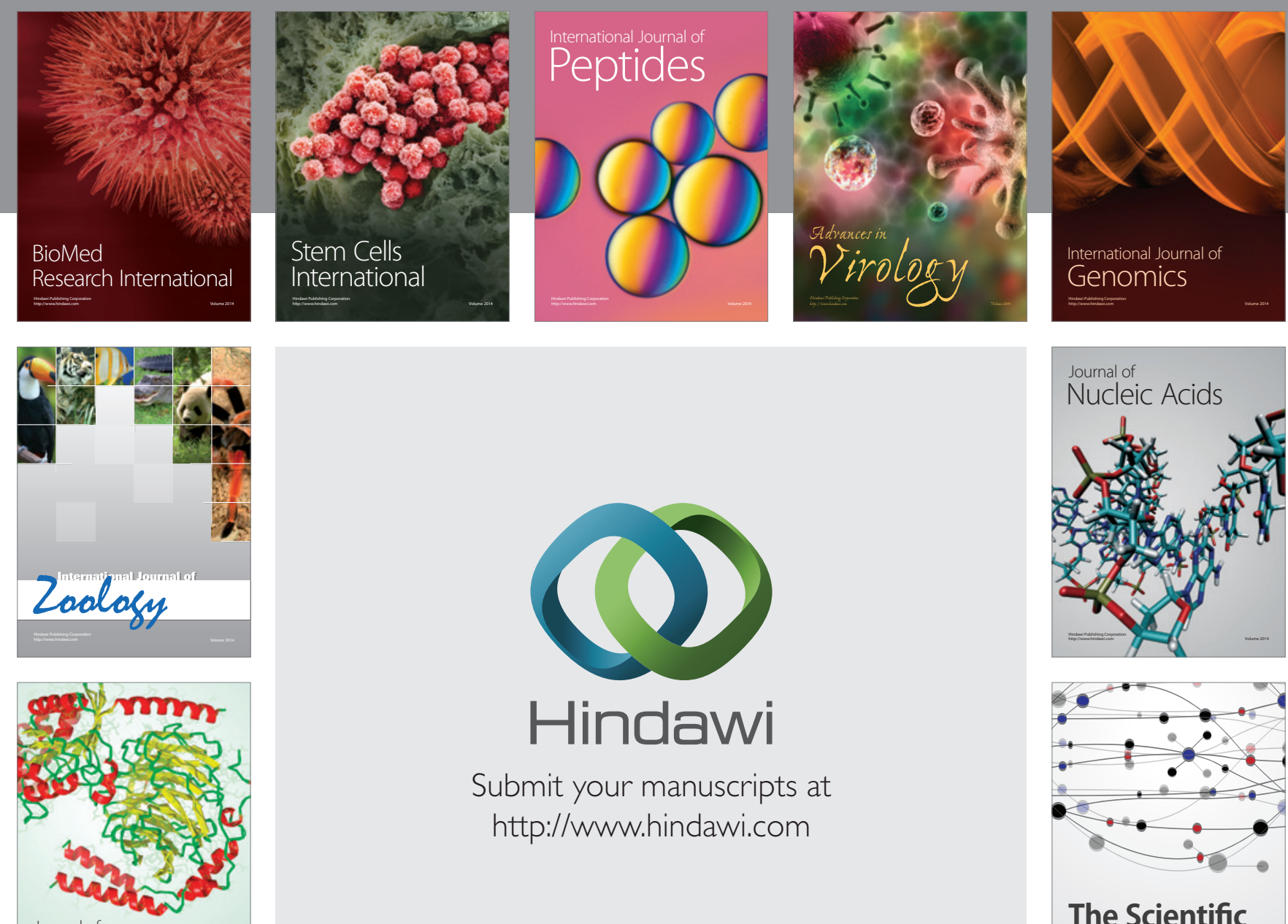

Submit your manuscripts at

http://www.hindawi.com

Journal of
Signal Transduction
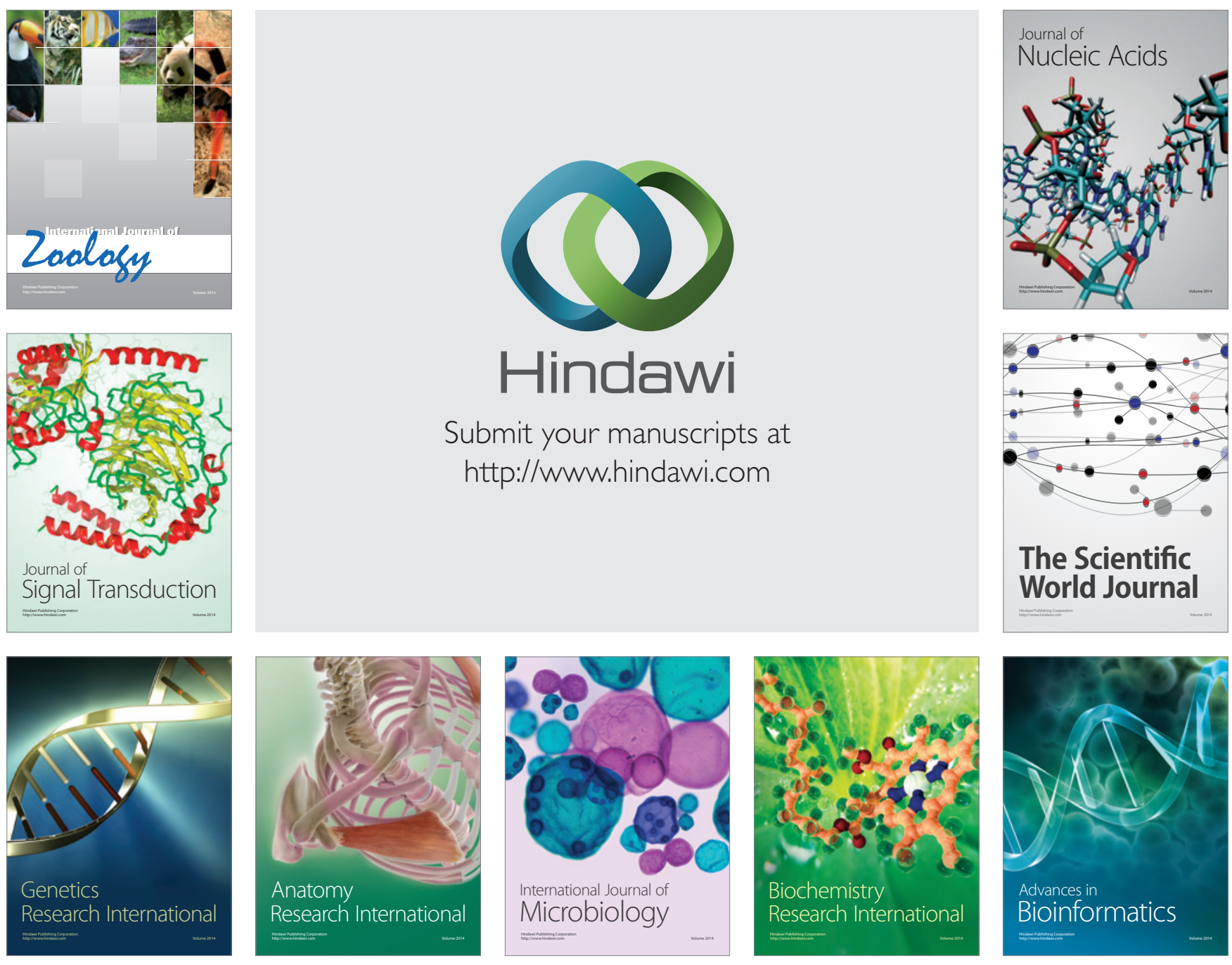

The Scientific World Journal
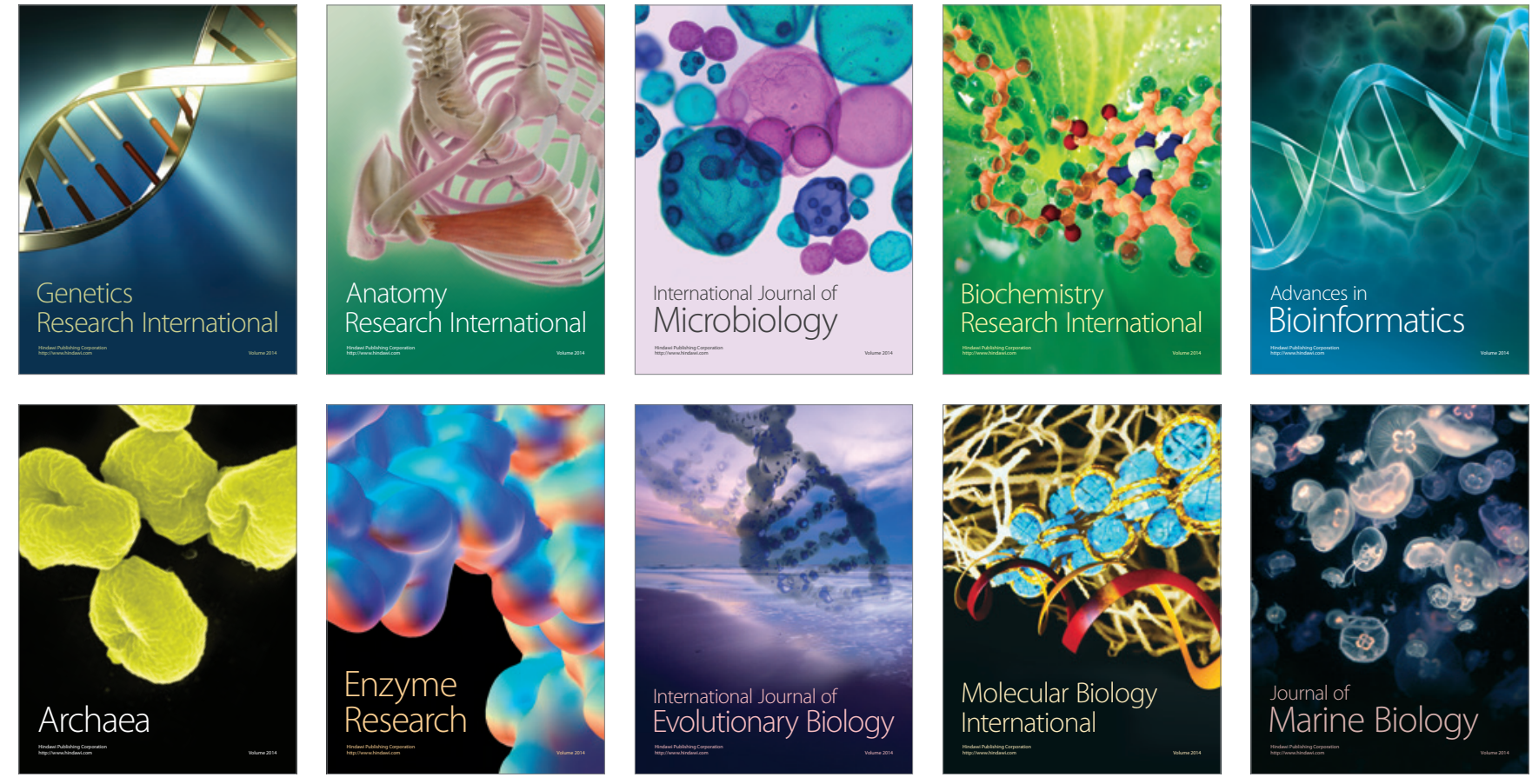